\title{
First Choice Lipid-Lowering Treatment of Hypercholesterolemias
}

\author{
Sidney Carvalho Fernandes ${ }^{1}$, Anita L. R. Saldanha ${ }^{1}$, Ana Paula Pantoja Margeotto ${ }^{1}$,André Luiz Valera Gasparoto ${ }^{2}$, Tania Leme da Rocha \\ Martinez ${ }^{1 *}$ \\ ${ }^{1}$ Nephrology Department, BP - A Beneficência Portuguesa de São Paulo, São Paulo, Brazil.
}

${ }^{2}$ Intensive Care Unit, BP - A Beneficência Portuguesa de São Paulo, São Paulo, Brazil.

*Corresponding author: Tania Leme da Rocha Martinez, Nephrology Department, BP - A Beneficência Portuguesa de São Paulo, São Paulo, Brazil

Received Date: February 09, 2021; Accepted Date: March 15, 2021 ; Published Date: March $16,2021$.

Citation: Sidney C Fernandes, Anita L. R. Saldanha, Ana P P Margeotto,André L V Gasparoto, Tania L R Martinez . (2021) First Choice LipidLowering Treatment of Hypercholesterolemias. Journal of Cardiology Research and Reports, 3(1): Doi: 10.31579/2692-9759/014

Copyright: (C) 2021, Tania Leme da Rocha Martinez. This is an open-access article distributed under the terms of the Creative Commons Attribution License, which permits unrestricted use, distribution, and reproduction in any medium, provided the original author and source are credited.

\begin{abstract}
Several recent studies with lipid-lowering substances have shown a significant reduction in complications of this disease with drastic reduction of LDL-cholesterol levels. However, a huge proportion of patients in secondary prevention remain with inefficient treatment. Vastatins, also called statins, are considered worldwide as the firstline pharmacotherapy for the treatment of hypercholesterolemia, being the most efficient drugs to lower LDLcholesterol, still presenting excellent tolerability. The main mechanism of action of vastatins is inhibition of the enzyme hydroxymethylglutaril-coenzyme A (HMG-CoA) reductase. Currently, the therapeutic arsenal for cases of family hypercholesterolemia and statin intolerance incorporated PCSK9 inhibitors (proprotein convertase subtilisin/kexin type 9) which is an enzyme that is involved in the degradation of the LDL- cholesterol receptor in the lysosome, preventing its recycling to the cell surface, thus reducing the amount of LDL-cholesterol receptors available, with consequent elevation of this lipid. Mutations with gain of function that lead to an increase in the expression of this enzyme cause, therefore, an increase in LDL- cholesterol, while mutations that lead to a decrease in its expression decrease LDL-cholesterol.
\end{abstract}

Keywords: hypercholesterolemia; statins; pleiotropic actions; HMG-CoA reductase; PCSK9 inhibitors

\section{Abbreviations}

Apo A-1: Apoprotein A-1

HMG-CoA: hydroxymethylglutaril-coenzyme A

LDL-C: low density lipoprotein cholesterol

VLDL: very low density lipoprotein

\section{Lipid-lowering substances}

Several recent studies [1-6] with lipid-lowering substances have shown a significant reduction in complications of this disease with drastic reduction of low density lipoprotein cholesterol (LDL-C) levels. However, a huge proportion of patients in secondary prevention remain with inefficient treatment. [7, 8]

Pharmacological treatment of dyslipidemias is indicated primarily for patients at medium and high risk for atherosclerosis and acute pancreatitis. The higher the patient's risk, the greater the benefit with the use of lipid-lowering substances. The treatment should be permanent and the longer the time of use of the drug, the greater the benefit achieved.

In addition, some points should be checked before the beginning of drug treatment: whether all preparation and planning of the case were complete; whether the goals of LDL-C and other lipid parameters were calculated; if dyslipidemia is not secondary (e.g., hypothyroidism, kidney disease, liver disease, drug use, alcoholism); whether dietary treatment and lifestyle changes (lifestyle change, with recommendation for physical activity, smoking cessation and alcoholism when applicable) have already been implemented and whether the selection of the drug is ideal for the treatment of dyslipidemia and cardiovascular risk (or pancreatitis) for the patient in question.

The indication for the use of lipid-lowering substances is set out in Chart 1. [9] 


\begin{tabular}{|l|l|l|l|}
\hline Lipid values (mg/dl) & High risk of atherosclerosis & $\begin{array}{l}\text { Medium risk of } \\
\text { atherosclerosis }\end{array}$ & $\begin{array}{l}\text { Low } \\
\text { atherosclerosis }\end{array}$ \\
\hline LDL-C $>190$ & Immediate + Lifestyle change & $\begin{array}{l}\text { Immediate + Lifestyle } \\
\text { change }\end{array}$ & $\begin{array}{l}\text { Immediate + Lifestyle } \\
\text { change }\end{array}$ \\
\hline LDL-C $>160$ & Immediate + Lifestyle change & $\begin{array}{l}\text { Immediate + Lifestyle } \\
\text { change }\end{array}$ & $\begin{array}{l}\text { After 3 months of lifestyle } \\
\text { change }\end{array}$ \\
\hline LDL-C $>130$ & Immediate + Lifestyle change & $\begin{array}{l}\text { After 3 months of lifestyle } \\
\text { change }\end{array}$ & $\begin{array}{l}\text { After } 6 \text { months of lifestyle } \\
\text { change }\end{array}$ \\
\hline LDL-C 100 to 130 & Immediate + Lifestyle change & Lifestyle change & Lifestyle change \\
\hline LDL-C $>100$ & AMD* + Lifestyle change & Lifestyle change & Lifestyle change \\
\hline Triglycerides $\geq 500$ & Immediate + Lifestyle change & $\begin{array}{l}\text { Immediate + Lifestyle } \\
\text { change }\end{array}$ & $\begin{array}{l}\text { Immediate + Lifestyle } \\
\text { change }\end{array}$ \\
\hline Triglycerides 150 to 499 & Lifestyle change & Lifestyle change & Lifestyle change \\
\hline
\end{tabular}

Chart 1: Indications of lipid-lowering substances

LDL-C = Low Density Lipoprotein. *At medical discretion, based on studies such as HPS, [9] PROVE-IT TIMI 22 [1] REVERSAL, [2] TNT, [3] ASTEROID [5] (it is suggested here to discuss with the patient the advantages and disadvantages of using pharmacotherapy for joint decisionmaking).

The following will be discussed the various types of substances available for the treatment of dyslipidemias.

Vastatins: also called statins, are considered worldwide as the first-line pharmacotherapy for the treatment of hypercholesterolemia, being the most efficient drugs to lower LDL-C, still presenting excellent tolerability. According to Roberts, [10] vastatins are for atherosclerosis just as penicillin is for infectious diseases. These substances reduce the risk of death, myocardial infarction, need for myocardial revascularization and ischemic stroke around $30 \%$, as shown by the MRC/BHF studies, [11] 4S, [12] CARE, [13] LIPID, [14] WOSCOPS, [15] AFCAPS/TexCAPS, [16] ASCOT-LLA, [17] LIPS,[18] CARDS, [19] MIRACL, [20] JUPITER, [6] and also slow progression or even lead to regression of atherosclerotic disease, as shown in REVERSAL [1] and ASTEROID studies [5].

It is important to note that this benefit occurred in secondary prevention studies with high cholesterol (4S), with low cholesterol (LIPID); borderline values (CARE); with in-normal cholesterol and with patients with values considered even low (HPS); primary prevention with high values (WOSCOPS); (AFCAPS/TexCAPS); in the primary prevention group for cardiovascular events in hypertensive patients (ASCOT) and diabetics (CARDS); patients with stabilized coronary disease (4S, CARE) or acute ischemic syndrome (MIRACL).

Mechanism of action: The main mechanism of action of vastatins is inhibition of the enzyme hydroxymethylglutaril-coenzyme A (HMG$\mathrm{CoA})$ reductase. This enzyme is responsible for catalyzing the reaction that transforms HMG-CoA into mevalonate, a reaction that is the limiting factor of cholesterol synthesis.

Inhibition of this reaction leads to a decrease in cholesterol synthesis, with an increase in the expression of LDL hepatic receptors, which leads to a more pronounced removal of LDL lipoprotein particles from plasma. The induction of the LDL receptor gene occurs by the action of SREBP (steroid responsive element binding-protein), one of the peptides responsible for intracellular cholesterol homeostasis [21].

Vastatins also lead to a decrease in triglycerides that is more modest than cholesterol, being more evident when there is hypertriglyceridemia above $250 \mathrm{mg} / \mathrm{dl}$. The mechanism for this effect may be by an increase in the removal of very low density lipoprotein (VLDL) from plasma by the greater expression of LDL receptors or even by a decreased hepatic production of VLDL by the liver. [22]

In addition to decreasing triglycerides, the reduction of the hepatic synthesis of VLDL also leads to a drop in LDL-C, which is independent of the increase in LDL receptor expression, as shown by the study by Raal et al., [23] in which, in 35 patients with homozygous family hypercholesterolemia, atorvastatin at a dose of $80 \mathrm{mg} /$ day led to a decrease in LDL-C by $28 \%$, and of these patients, 30 had a residual activity of the LDL receptor; however, 5 were negative receptors and obtained the same reduction rate, and this reduction was obtained with the reduction of VLDL synthesis (and, consequently, LDL).

Effectiveness: All vastatins produce a significant reduction in LDL-C (between 18 and 58\%), with a more slight decrease in triglycerides (between 7 and 30\%) and a small increase in HDL-C (between 5 and $15 \%)$.

Chart 2 shows the effect of several vastatins on different dosages on the decrease in LDL-C.

It is observed that the least potent vastatine is fluvastatin and the most potent, rosuvastatin. It is also verified that, when doubling the dose of vastatin, the reducing effect of LDL-C increases by only $6 \%$ on average, and this fact is an important limiting factor to achieve the LDL-C goals recommended by the current guidelines.

\begin{tabular}{|l|l|l|l|l|}
\hline Vastatin & $10 \mathrm{mg}$ & $20 \mathrm{mg}$ & $40 \mathrm{mg}$ & $80 \mathrm{mg}$ \\
\hline Fluvastatin & 15 & 22 & 27 & 34 \\
\hline Pravastatin & 22 & 25 & 30 & - \\
\hline Lovastatin & 22 & 27 & 31 & 39 \\
\hline Sinvastatin & 23 & 28 & 34 & 41 \\
\hline Atorvastatin & 41 & 44 & 50 & 55 \\
\hline Rosuvastatin & 46 & 52 & 56 & - \\
\hline
\end{tabular}




\section{LDL-C = low-density lipoprotein}

There is also a great variation in the response to the effect of vastatins, which may be due to genetic or environmental factors.

Among the genetic factors that affect the response to vastatin, what has received greater attention is the ApoE gene, which can present three isoforms: e2, e3 and e4, and one individual may have six different genotypes: homozygote e2, e3 and e4 or heterozygotes e2/e3, e2/e4 and e3/e4, knowing that the homozygous genotype e 2 is the one with the highest response, followed by homozygote e 3 and homozygous e4 [24]. On the contrary, homozygous patients e4 respond better to the diet. This seems to occur because carriers of the e 4 allelo are better absorbers of dietary cholesterol, with cholesterolemia being less dependent on the cellular synthesis of cholesterol and, therefore, less sensitive to its inhibition.

Among the extrinsic factors that can alter the response to vastatins, the main ones are:

\section{Adherence to diet}

- Administration hours, being recommended its use in the evening after dinner, due to the circadian rhythm of activity of HMG-CoA reductase, which is more active at night

- Ingestion of foods containing fibers, mainly pectin and oat meal, together with vastatins can lead to a decrease in their absorption [25].

- Concomitant administration of other drugs, especially those that are metabolized by cytochrome P450 3A4. In this regard, substances that induce this enzymatic system (carbamazepine, diphenyl-hyantoin, rifampicin) decrease the effect of lovastatin, sinvastatin and atorvastatin, while inhibitory substances of this system (cyclosporine, amiodarone, diltiazem) increase the concentration of these drugs and consequently their effect. Pravastatin, fluvastatin and rosvastatin, which do not have their metabolism dependent on cytochrome P450 3A4, no longer suffer as much interference from drugs that alter this system.

Pleiotropic effects: in addition to the effects that improve the lipid profile, vastatins have important antiatherosclerotic vascular effects, with improvement of endothelial function, decrease in the load of atheroma determined by intravascular ultrasound and also anti-inflammatory and immunomodulatory effects, which lead to reduced morbidity and mortality. However, it is discussed whether these effects are due only to the fact that vastatins reduce LDL-C or if these drugs have other actions independent of it. The mevalonate, in addition to a cholesterol precursor, is also of prenilated proteins, which are part of the cell signaling cascade that affects the proliferation of smooth muscle cells [26, 27] and also of geranilgeranil phosphate and ubiquinone which are important components in several intracellular inflammatory signaling cascades. Therefore, the decrease in the synthesis of these substances, by inhibiting the formation of mevalonate, leads to less efficient inflammatory cell signaling, resulting in decreased inflammatory cytokines.

It is also observed that vastatins, in addition to reducing LDL-C, have other lipid effects: they increase absorption by endocytosis, degradation and prevent LDL oxidation, decrease LDL accumulation in macrophages, interfere in lipoprotein secretion and increase the expression of SRB1 receptors, important in reverse cholesterol transport.

It was also verified that vastatins selectively inhibit leukocyte function antigen-1 [28] LFA-1 (also called aL-b2 or CD11a/CD18), a heterodum that belongs to the family of $b_{2}$ integrin and is involved in lymphocytic recirculation, leukocyte scans at inflammation sites and activation of $\mathrm{T}$ cells by antigen-presenting cells. This effect is independent of the inhibition of HMG-CoA reductase and occurs by chemical binding of vastatins in an allosteric site within LFA-1, causing inhibition of the receptor. This property of vastatins has been explored in studies for the treatment of psoriasis, rheumatoid arthritis, ischemia/reperfusion injury and transplant rejection.

Perhaps related to this inhibition and/or also to the interference in the formation of geranilgeranil phosphate and ubiquinone, is the effect related to the decrease in transplant vasculopathy and the increase in survival that is observed with the use of vastatins in transplanted patients.

Regarding cognitive function, there does seem to actually be a link between hypercholesterolemia and Alzheimer's disease. Some studies show the protective effect of vastatins, but not other lipid-lowering factors, in the prevention of cognitive dysfunction $[29,30]$.

Still very debatable and awaiting the results of studies, is the effect of vastatins on the improvement in osteoporosis and faster consolidation of bone fractures.

Regarding the action of vastatins on bone metabolism, all recent data available in the literature suggest a positive effect of these drugs on bone mass, through 2 types of effects: inhibition of reabsorption and stimulation of bone formation (anti-resorption and anabolic effects). Therefore, in the near future, vastatins may appear among the substances used in the prevention and treatment of osteoporosis, mainly due to the current familiarity of clinicians with their use [31].

A beneficial effect of vastatin has also been shown to prevent thromboembolism and thromboembolic phenomena. ${ }^{32}$ In this study, which randomized healthy men and women, the use of rosvastatin was also demonstrated, the use of rosvastatin was associated with a $36 \%$ reduction in the risk of thromboembolism, an effect that appears to be an independent benefit from the use of this vastatin, in addition to reducing the risk of arterial thrombosis. Expanding the treatment objective to include thromboembolism prevention and death, in addition to arterial thrombosis, significantly increases the estimated benefit of the use of vastatins.

Safety and tolerability: vastatins are substances that have an excellent safety profile, with a very low incidence of side effects, the most important being hepatotoxicity and myopathy.

Asymptomatic changes in hepatic transaminases occur in 2 to $5 \%$ of patients using vastatins, are temporary, reversible with drug suspension and do not lead to liver failure or permanent liver injury. It is recommended to discontinuation of the drug if transaminases exceed 3 times the higher normal values.

Myopathy accompanied by increased creatinephosphokinase (CPK) rarely occurs $(0.1 \%)$, as well as with rhabdomyolysis. Drugs (e.g., cyclosporine, antifungals, amiodarone, genfibrozil), hypothyroidism and women with low weight are associated with a higher incidence of myopathy and liver alterations, and these particular cases should be monitored with greater care.

Patients using vastatins should be instructed to immediately report symptoms of fatigue, muscle pain or weakness, fever, dark urine, or any other symptom that appears shortly after the introduction of the drug or increased dosage, as side effects grow at higher doses.

Other side effects include epigastric pain or burning, abdominal pain, diarrhea, constipation, flatulence, headache, and urticariform or allergic skin lesions. These effects are rarely important to the point of leading to discontinuation of treatment.

The JUPITER [6] study showed a $28 \%$ increase in the incidence of diabetes mellitus in patients who used rosuvastatin. Further analysis of this study [33] found, however, that the benefits of reducing cardiovascular events and mortality associated with the use of rosuvastatin exceeded the risk of diabetes; it also showed that patients 
who developed diabetes were at increased risk for the development of this disease.

No study has shown an association with the use of vastatins with a high incidence of any type of cancer, anxiety, depression or other psychological changes.

Dosage: As has already been said, the synthesis of cholesterol is higher at night and in the early hours of the morning. Vastatins should therefore be

administered after dinner or at bedtime. It should start with a small dose, which should be increased until lipid targets can be achieved. If a significant reduction in LDL-C (50\%) is intended, it should be initiated with a more potent vastatin (e.g., atorvastatin, rosuvastatin or, as will be shown below, with an association). If a smaller reduction is desired, something around 20 to $30 \%$, one can start with any other vastatin. For the minimum and maximum doses, see Chart 3.

\begin{tabular}{|l|l|l|}
\hline Vastatin & $\begin{array}{l}\text { Minimum doses } \\
(\mathbf{m g} / \text { day })\end{array}$ & $\begin{array}{l}\text { Maximum doses } \\
(\mathbf{m g} / \text { day })\end{array}$ \\
\hline Fluvastatin & 20 & 80 \\
\hline Pravastatin & 20 & 40 \\
\hline Lovastatin & 20 & 80 \\
\hline Sinvastatin & 10 & 80 \\
\hline Atorvastatin & 10 & 80 \\
\hline Rosuvastatin & 5 & 40 \\
\hline
\end{tabular}

Chart 3: Minimum and maximum doses of the various vastatins.

Contraindications: vastatins are contraindicated in active liver disease, pregnancy and lactation, and in women of childbearing age, unless an efficient contraceptive method is used. They should also be suspended in conditions that may lead to renal failure due to rhabdomyolysis, such as septicemia, hypotension, major surgeries, polytraumatized patients, etc.

In summary, vastatins are the drugs of choice for the treatment of hypercholesterolemia. Its use, in general, is permanent. They should be administered daily after dinner.

To achieve a reduction in LDL-C for high-risk patients at levels recommended by the current guidelines, with a decrease of about $50 \%$ of baseline LDL-C, atorvastatin at a dose of $80 \mathrm{mg} /$ day and rosuvastatin at a dose of $20 \mathrm{mg} /$ day are more efficient. Vastatins can also be used in conjunction with drugs that have a different mechanism of action to obtain a synergism of action.

Contemporarily - Several drugs that are approved for clinical use. The following stand out:

PCSK9 inhibitors: PCSK9 (proprotein convertase subtilisin/kexin type 9) is an enzyme that is involved in the degradation of the LDL-C receptor in the lysosome, preventing its recycling to the cell surface, thus reducing the amount of LDL-C receptors available, with consequent elevation of this lipid. Mutations with function gain that lead to an increase in the expression of this enzyme therefore cause an increase in LDL-C, while mutations that lead to a decrease in its expression decrease LDL-C [34, 35 ]. Antibodies against this protein have been developed and are already in phase 3 studies of investigation, and release is expected for clinical use soon.

Mipomersen: is an oligonucleotide inhibitor of ApoB synthesis. To date, clinical studies with more than 800 patients have been researched, with four phase 3 randomized, double-blind, placebo-controlled studies involving approximately 400 patients. Mipomersen is rapidly absorbed after subcutaneous administration, has an average half-life of about 30 days. It is metabolized by the enzyme class of nucleases, with renal excretion of its metabolites. It is efficient in reducing all particles containing ApoB and can be used alone or in combination with other lipid-lowering substances, especially vastatins, obtaining a synergistic effect $[36,37,38]$.

Berberine: used in China for decades to treat diarrhea, is studied as a reduction of LDL-C, acting with increased expression of LDL receptor by a post-transcriptional mechanism. There are no clinical studies yet.
Apoprotein A-1 (Apo A1) mimetic peptides: they are a-helix peptides that form complexes with phospholipids, considered synthetic ApoA that, when injected, behave like the original ApoA, increasing HDL.

\section{Acknowledgments}

None.

\section{Conflicts of interest}

No conflict of interest.

\section{References}

1. Cannon CP, Braunwald E, McCabe CH Rader DJ, Rouleau JL, Belder R, et al. (2004) Intensive versus moderate lipid lowering with statins after acute coronary syndromes. The pravastatin or atorvastatin evaluation and infection therapy - thrombolysis in myocardial infarction 22 investigators. N Engl J Med. 350:14951504.

2. Nissen SE, Tuzcu EM, Schoenhagen P, Brown BG, Ganz P, Vogel RA, et al. (2004) Effect of intensive compared with moderate lipid-lowering therapy on progression of coronary atherosclerosis: a randomized controlled trial. JAMA. 291(9):1071-1080.

3. LaRosa JC, Grundy SM, Waters DD, Shear C, Barter P, Fruchart JC, et al. (2005) Treating to New Targets (TNT) Investigators. Intensive lipid lowering with atorvastatin in patients with stable coronary disease. N Engl J Med. 352(14):1425-1435.

4. Pedersen TR, Faergeman O, Kastelein JJ, Olsson AG, Tikkanen MJ, Holme I, et al. (2005) High-dose atorvastatin vs usual-dose simvastatin for secundary prevention after myocardial infarction: the IDEAL study: a randomized controlled trial. JAMA. 294(19):2437-2445.

5. Nissen SE, Nicholls SJ, Sipahi I, Libby P, Raichlen JS, Ballantyne CM, et al. (2006) Effect of very high-intensity statin therapy on regression of coronary atherosclerosis: the ASTEROID trial. JAMA.295(13): 1556-1565.

6. Ridker PM, Danielson E, Fonseca FA, Genest J, Gotto AM Jr, Kastelein JJ, et al. (2008) Rosuvastatin to prevent vascular events in men and women with elevated C-reactive protein. N Engl J Med.359(21):2195-2207.

7. EUROASPIRE. (1997) A European Society of Cardiology survey of secondary prevention of coronary heart disease: principal results. EUROASPIRE Study Group. European Action on Secondary Prevention through Intervention to Reduce Events. Eur Heart J.;18(10):1569-1582. 
8. Brown AS, Bakker-Arkema RG, Yellen L, Henley RW Jr, Guthrie R, Campbell CF, et al.( 1998) Treating patients with documented atherosclerosis to National Cholesterol Education Programrecommended low-density-llipoprotein cholesterol goals with atorvastatin, fluvastatin, lovastatin and simvastatin. J Am Coll Cardiol.;32(3):665-672.

9. Santos RD. (2004) Tratamento das dislipidemias. In: Lopes AC (ed.). Dislipidemias: da Teoria à Prática. 1. ed. São Paulo: Atheneu;. p. 395-397

10. Roberts WC. (1996) The underused miracle drugs: the statin drugs are to atherosclerosis what penicillin was to infectious diseases. Am J Cardiol.78(3):377-378.

11. Heart Protection Study Collaborative Group. (2002) MRC/BHF Heart Protection Study of cholesterol lowering with simvastatin in 20536 high-risk individuals: a randomised placebo-controlled trial. Lancet.360(9326):7-22.

12. Randomised trial of cholesterol lowering in 4444 patients with coronary heart disease: the Scandinavian Simvastatin Survival Study (4S). Lancet. 1994;344(8934):1383-1389.

13. Sacks FM, Pfeffer MA, Moye LA, Rouleau JL, Rutherford JD, Cole TG, Brown L, et al. (1996) The effect of pravastatin on coronary events after myocardial infarction in patients with average cholesterol levels. Cholesterol and Recurrent Events Trial investigators. N Engl J Med. 335(14):1001-1009.

14. Long-Term Intervention with Pravastatin in Ischaemic Disease (LIPID) Study Group. (1998) Prevention of cardiovascular events and death with pravastatin in patients with coronary heart disease and a broad range of initial cholesterol levels. N Engl J Med. 339(19):1349-1357.

15. Shepherd J, Cobbe SM, Ford I, Isles CG, Lorimer AR, MacFarlane PW, et al. (1995) Prevention of coronary heart disease with pravastatin in men with hypercholesterolemia. West of Scotland Coronary Prevention Study Group. N Engl J Med. 333(20):1301-1307.

16. Downs JR, Clearfield M, Weis S, Whitney E, Shapiro DR, Beere PA, et al. (1998) Primary prevention of acute coronary events with lovastatin in men and women with average cholesterol levels: results of AFCAPS/TexCAPS. Air Force/Texas Coronary Atherosclerosis Prevention Study. JAMA. 279(20):1615-1622.

17. Sever PS, Dahlöf B, Poulter NR, Wedel H, Beevers G, Caulfield M, et al. (2003) Prevention of coronary and stroke events with atorvastatin in hypertensive patients who have average or lowerthan-average cholesterol concentrations, in the AngloScandinavian Cardiac Outcomes Trial-Lipid Lowering Arm (ASCOT-LLA): a multicentre randomised controlled trial. Lancet.;361(9364):1149-1158.

18. Saia F, de Feyter P, Serruys PW, Lemos PA, Arampatzis CA, Hendrickx GR, et tal. (2004) Effect of fluvastatin on long-term outcome after coronary revascularization with stent implantation. Am J Cardiol. 93(1):92-95.

19. Colhoun HM, Betteridge DJ, Durrington PN, Hitman GA, Neil HA, Livingstone SJ, et al. (2004) Primary prevention of cardiovascular disease with atorvastatin in type 2 diabetes in the Collaborative Atorvastatin Diabets Study (CARDS): multicentre randomised placebo-controlled trial. Lancet. 364(9435):685-696.

20. Schwartz GG, Olsson AG, Ezekowitz MD, Ganz P, Oliver MF, Waters D, et al. (2001) Effects of atorvastatin on early recurrent ischemic events in acute coronary syndromes: the MIRACL study: a randomized controlled trial. JAMA. 285(13):1711-1718.

21. Horton JD, Goldstein JL, Brown MS. (2002) SREBPs: activators of the complete program of cholesterol and fatty acid synthesis in the liver. J Clin Invest. 109(9):1125-1131.
22. Ginsberg HN, Le NA, Short MP, Ramakrishnan R, Desnick RJ. (1987) Suppression of apolipoprotein B production during treatment of cholesteryl ester storage disease with lovastatin. Implications for regulation of apolipoprotein B synthesis. J Clin Invest. 80(6):1692-1697.

23. Raal FJ, Pappu AS, Illingworth DR, Pilcher GJ, Marais AD, Firth JC, et al. (2000) Inhibition of cholesterol synthesis by atorvastatin in homozygous familial hypercholesterolemia. Atherosclerosis. 15092):421-428.

24. Ordovas JM, Mooser V. (2002) The APOE locus and the pharmacogenetics of lipid response. Curr Opin Lipidol.13(2):113117.

25. Richter WO, Jacob BG, Schwandt P. (1991) Interaction between fibre and lovastatin. Lancet. 338(8768):706.

26. Goldstein JL, Brown MS. (1990) Regulation of the mevalonate pathway. Nature. 343(6257):425-430.

27. Glomset JA, Gelb MH, Farnsworth CC. (1990) Prenyl proteins in eukaryotic cells: a new type of membrane anchor. Trends Biochem Sci.15(4):139-142.

28. Weitz-Schmidt G, Welzenbach K, Brinkmann V, Kamata T, Kallen J, Bruns C, et al. (2001) Statins selectively inhibit leukocyte function antigen-1 by binding to a novel regulatory integrin site. Nat Med.7(6):687-692.

29. Grady D, Yaffe K, Kristof M, Lin F, Richards C, Barrett-Connor E. (2002) Effect of postmenopausal hormone therapy on cognitive function: the Heart and Estrogen/progestin Replacement Study. Am J Med.113(7):543-548. -9343.

30. Wolozin B, Kellman W, Ruosseau P, Celesia GG, Siegel G. (2000) Decreased prevalence of Alzheimer disease associated with 3-hydroxi-3-methyglutaryl coenzyme A reductase inhibitors. Arch Neurol.57(10):1439-1443.

31. Tsartsalis AN, Dokos C, Kaiafa GD, Tsartsalis DN, Kattamis A, Hatzitolios AI, et al. (2012) Statins, bone formation and osteoporosis: hope or hype? Hormones (Athens).11(2):126-139.

32. Glynn RJ, Danielson E, Fonseca FA, Genest J, Gotto AM Jr, Kastelein JJ, et al. (2009) A randomized trial of rosuvastatin in the prevention of venous thromboembolism. N Engl $\mathrm{J}$ Med.360(18):1851-1861.

33. Ridker PM, Pradhan A, MacFadyen JG, Libby P, Glynn RJ. (2012) Cardiovascular benefits and diabetes risks of statin therapy in primary prevention: an analysis from the JUPITER trial.;380(9841):565-571.

34. Peterson AS, Fong LG, Young SG. (2008) PCSK9 function and physiology. J Lipid Res.;49(7):1595-1599.

35. Scartezini M, Hubbart C, Whittall RA, Cooper JA, Neil AH, Humphries SE. (2007) The PCSK9 gene R46L variant is associated with lower plasma lipid levels and cardiovascular risk in healthy U.K. men. Clin Sci (Lond).113(11):435-441.

36. Crooke ST, Geary RS. (2013) Clinical pharmacological properties of mipomersen (Kynamro), a second generation antisense inhibitor of apolipoprotein B.76(2):269-276.

37. Raal FJ, Santos RD, Blom DJ, Marais AD, Charng MJ, Cromwell WC, et al. (2010) Mipomersen, an apolipoprotein B synthesis inhibitor, for lowering of LDL cholesterol concentrations in patients with homozygous familial hypercholesterolaemia: a randomised, double-blind, placebo-controlled trial.375(9719):998-1006.

38. Stroes ES. (2010) Apolipoprotein B synthesis inhibition: results from clinical trials. Curr Opin Lipidol. 21(4):319-323. 